\title{
Pathological complete response following neoadjuvant radiotherapy and intraperitoneal perfusion chemotherapy for recurrent colon carcinoma: A case report and literature review
}

\author{
XINYU BIAN, BAORUI LIU and YANG YANG
}

The Comprehensive Cancer Centre of Drum Tower Hospital, Medical School of Nanjing University and Clinical Cancer Institute of Nanjing University, Nanjing, Jiangsu 210008, P.R. China

Received January 4, 2015; Accepted February 4, 2016

DOI: $10.3892 / 01.2016 .4299$

\begin{abstract}
The present study reports the case of a 28-year-old male who was diagnosed with sigmoid colon carcinoma and exhibited local recurrence following radical surgery and 6 cycles of adjuvant chemotherapy. The primary surgery consisted of a partial sigmoidectomy and bladder repair. At 8 months post-chemotherapy, the patient was referred to Nanjing Drum Tower Hospital (Nanjing, China) due to local recurrence at the anastomotic site, which was confirmed by colonoscopy and total abdominal computed tomography. Synchronous intensity modulation radiation therapy and intraperitoneal (IP) perfusion chemotherapy with irinotecan $\left(100 \mathrm{mg} / \mathrm{m}^{2}\right)$ was administered. Following treatment, the object efficacy evaluation revealed a complete response and a second resection of the remaining sigmoid colon was performed. The post-operative results showed a pathological complete response. This case indicated that a combination of therapies, including radiotherapy, IP perfusion chemotherapy and surgery, may be beneficial and effective in patients with recurrent colon cancer.
\end{abstract}

\section{Introduction}

Colorectal cancer (CRC) is the third most commonly diagnosed cancer in males worldwide and the second most common in females, with an estimated 1.4 million cases occurring in 2012 (1). There are no typical symptoms until the late stages of the disease, which may then include abdominal pain, hematochezia and change of stool customs. Two thirds of CRC cases are colon cancer (2), for which the main treatment is radical surgery. Approximately $40 \%$ of

Correspondence to: Dr Yang Yang, The Comprehensive Cancer Center of Drum Tower Hospital, Medical School of Nanjing University and Clinical Cancer Institute of Nanjing University, 321 Zhongshan Road, Nanjing, Jiangsu 210008, P.R. China

E-mail:wing_young7@hotmail.com

Key words: recurrent colon cancer, neoadjuvant therapy, pathological complete response patients experience recurrence, and this is consequently the main cause of mortality among affected individuals (3). It has been reported that the average survival time for patients with tumor recurrence is 7 months, which can be increased to $\sim 29.9$ months when a second surgery is performed (4). For this reason, when treating patients with recurrent colon cancer, the main aim is to achieve a radical resection or to at least perform palliative surgery.

Neoadjuvant chemoradiotherapy is a feasible option in order to realize an R0 resection for local recurrent colon cancer. Perioperative radiation therapy and chemotherapy can also reduce the recurrence rate and prolong the survival time of patients (5-7). Irinotecan (CPT-11) has shown anti-tumor effects in multiple types of tumor is also used in the neoadjuvant chemotherapy for colon cancer (8). Intraperitoneal (IP) chemotherapy with CPT-11 is also applied to treat various intra-abdominal tumors, including colon cancer $(9,10)$. Intensity-modulated radiotherapy (IMRT) has been widely applied in the treatment of cancer due to its potential to provide sharp dose gradients at the junction of the tumor and the adjacent critical organs. It is considered to be safe and effective, and may be applied in the treatment of various types of cancer (11).

The present study reports a case of locally recurrent colon cancer, in which a radical reoperation was performed following neoadjuvant IMRT and IP chemotherapy. Written informed consent was provided by the patient for publication of this study. The study was approved by the Ethics Committee of Nanjing Drum Tower Hospital (Nanjing, China).

\section{Case report}

A 28-year-old man experienced hematochezia for 6 months and was first diagnosed with sigmoid colon carcinoma by colonoscopy at the People's Hospital of Suqian City (Suqian, China) on June 1, 2012. The patient underwent a partial sigmoidectomy and surgical bladder repair. The pathological diagnosis was of a grade I-II adenocarcinoma of the sigmoid colon, according to Broders (12) carcinoma grading system, of which 50\% was mucoid carcinoma. The carcinoma invaded the full-thickness of the colon wall and the muscle layer of the bladder. No lymph node metastasis was evident (0/29 nodes). 


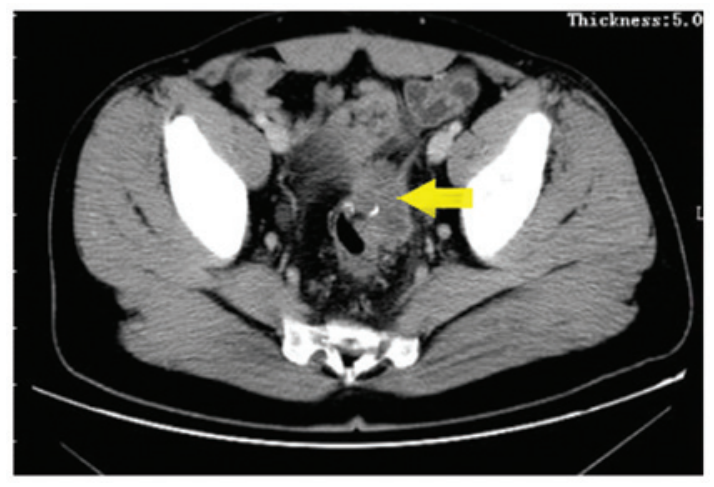

Figure 1. Computed tomography revealing a tumor (arrow) at the anastomotic site.

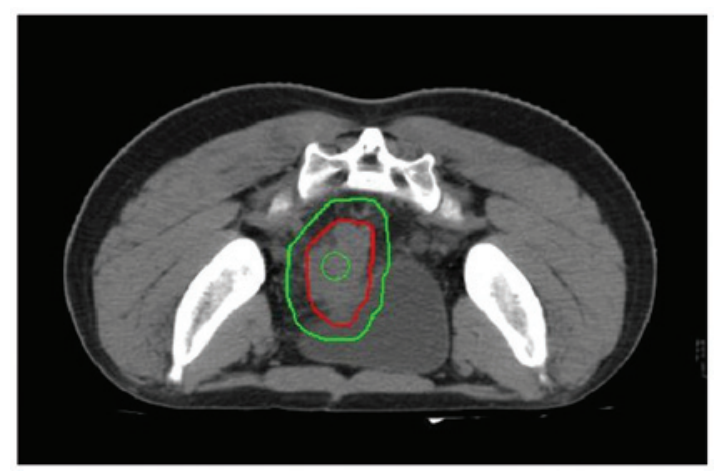

Figure 2. Computed tomography showing the dose distribution of radiotherapy. The green lines represent the PTV isodose and the red line represents the PTV1 isodose.

The patient then underwent 6 cycles of a docetaxel combined with oxaliplatin, 5 -fluorouracil and calcium folinate regimen (detailed treatment dosage data were not available). The serum levels of carcinoembryonic antigen (CEA), cancer antigen (CA)19-9, CA-125 and CA242 during the whole course were normal.

At 8 months post-adjuvant chemotherapy, the patient was presented to Nanjing Drum Tower Hospital on October 23, 2013, due to hematochezia that had persisted for several days. Laboratory tests revealed normal levels of tumor markers, including CEA, CA19-9, CA125 and CA242. Computed tomography (CT) scans revealed a mass, $\sim 4.2 \mathrm{~cm}$ in diameter, at the anastomotic site, invading the bladder and the left ureter (Fig. 1). No other metastases in the abdominal organs or lymph nodes were detected by CT. Colonoscopy biopsy revealed grade II adenocarcinoma, which was conjectured to be the result of the recurrence of the primary tumor.

The patient was treated by a multidisciplinary team, including surgeons, radiation oncologists and physicians. As the carcinoma encroached on the surrounding organs, the surgeons indicated that it was not possible to perform a radical resection and that pre-operative neoadjuvant therapy was necessary. The patient was then administered intensity modulation radiation therapy (IMRT). The planning target volume (PTV) consisted of the clinical target volume plus a 0.8 to $1-\mathrm{cm}$ margin, and the PTV1 (a region of the PTV with a higher dose) consisted of the gross tumor volume plus

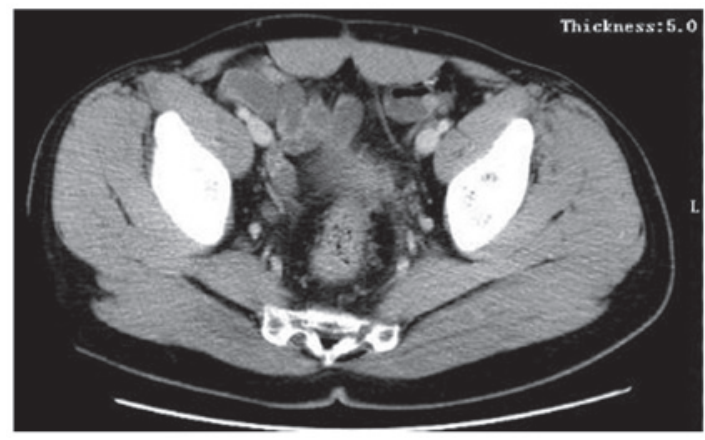

Figure 3. Computed tomography scan 2 months after neoadjuvant therapy. Objective evaluation indicated complete remission.

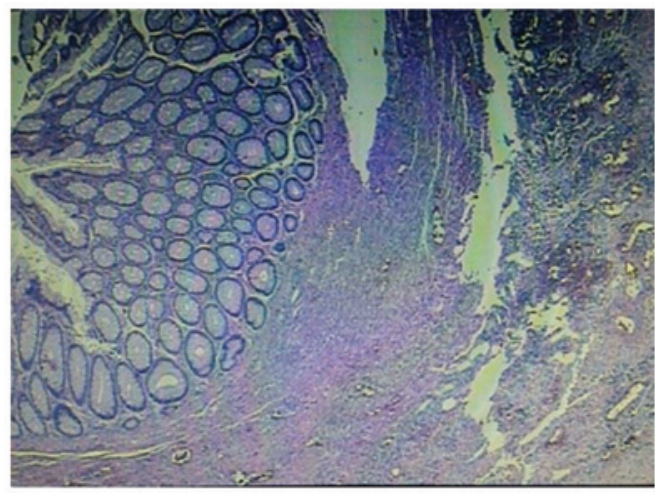

Figure 4. Hematoxylin and eosin-stained section showing a complete response (no residual tumor cells).

a 0.3-cm margin. The total dose prescription for the PTV was $50 \mathrm{~Gy}$ and the total dose prescription for the PTV1 was $60 \mathrm{~Gy}$, which were each delivered at 2 Gy per fraction (Fig. 2). The radiotherapy was delivered over 6 weeks. Concurrent IP perfusion chemotherapy using CPT-11 $\left(100 \mathrm{mg} / \mathrm{m}^{2}\right)$ was administered weekly, five times during the radiotherapy course (Fig. 2).

Following the concurrent radiation therapy and chemotherapy, CT scans revealed no evident tumor at the anastomotic site or any other metastases, indicating a clinical complete response (Fig. 3). Subsequently, the patient underwent a second surgery to resect the remaining sigmoid colon. The pathological examination revealed no definite invasive adenocarcinoma or lymph node metastasis, thus, the patient achieved a pathological complete response (pCR) (Fig. 4). Four additional 4-week cycles of intravenous (IV) systemic CPT-11 chemotherapy $\left(150 \mathrm{mg} / \mathrm{m}^{2}\right.$, days 1 and 15) combined with oral Xeloda $\left(1,500 \mathrm{mg} / \mathrm{m}^{2}\right.$, days $\left.1-14\right)$ were administered. At the time of writing this study, the patient remains alive, with a disease-free survival time of $\sim 10$ months.

\section{Discussion}

The majority of colon cancer local recurrences occur at 6 months to 2 years after the first surgery (13). While $30-40 \%$ of patients with stage II/III colon cancer experience recurrence, only $10-20 \%$ of them can undergo radical surgery $(14,15)$. It has also been reported that the 5 -year survival rate may be $19-35 \%$ for patients who undergo a second radical surgery, 
but $<5 \%$ for inoperable patients. Radical surgery can prolong survival markedly, with the 5-year survival rate increasing up to $54 \%$; even in patients who exhibit positive surgical margins, the 5-year survival rate can increase to $25 \%(14,16,17)$.

In the present case, the patient experienced recurrence after surgery and 6 cycles of adjuvant chemotherapy. However, according to the surgeons, the tumor could not be removed via radical surgery and so neoadjuvant medical treatment was a requisite. CPT-11, a widely used second-line anticancer agent, which has been shown to have cytotoxic activity in patients with colorectal, gastric, pancreatic, lung, ovarian, breast and cervical cancers, was chosen for application. In the liver and other tissues, carboxyl esterase converts CPT-11 to its active metabolite, SN-38, which is potently inhibits the nuclear enzyme, topoisomerase I. This enzyme exhibits cytotoxic activity that is 100-1,000-fold greater than that of CPT-11 (18). CPT-11 has been demonstrated to extend the overall survival of metastatic colorectal cancer patients when an IV administration (19). In a mouse model, IP administration of CPT-11 was significantly more effective than IV administration with regard to antitumor activity against peritoneal seeding and liver metastases (20). The survival benefit of IP chemotherapy has been documented in ovarian and gastric cancer, for which randomized trials showed significant a survival advantage for patients receiving IP chemotherapy (21-23). An IP CPT-11 pharmacokinetic study performed in a pig model confirmed the ability of the drug to achieve a peritoneal exposure level at least 30 times higher than that of systemic exposure. The peak concentration of peritoneal SN-38 was also achieved earlier than that of plasma SN-38, suggesting that IP infusion of CPT-11 could be an efficient route of administration in patients with abdominal carcinomas (24).

Unlike recurrent rectal cancer, recurrent colon cancer is not commonly treated with radiotherapy for the unfixed lesions and radioactive enteritis of the surrounding small intestines. However, technological advances in radiation treatment, particularly planning IMRT, have developed the practice, particularly for the treatment of multiple tumors, while minimizing the risk of damage to healthy tissues (25-27). IMRT has been applied to treat recurrent colon cancer according to the National Comprehensive Cancer Network treatment guidelines (28). In the present study, prior to receiving the treatment, the patient expressed a strong desire to undergo an anus-preserving procedure, which is difficult to achieve surgically. The patient later refused to undergo a second surgery and a radiotherapy plan was formulated with the aim of a radical cure. However, at the end of radiotherapy, the patient decided to undergo the required surgery. The post-operative pathological result revealed a pCR following neoadjuvant therapy, which usually occurs at a low rate, but allows for improved survival times. It has been reported that the cumulative 5-year survival rates may reach $75 \%$ for patient with a pCR $(29,30)$.

In conclusion, in the present case, a patient with recurrent colon cancer was effectively treated by a multidisciplinary treatment that included IMRT, IP perfusion chemotherapy and a second surgery. A pCR was achieved, indicating that IMRT combined with IP perfusion chemotherapy using CPT-11 may be a feasible neoadjuvant therapy for recurrent colon cancer.

\section{References}

1. Torre LA, Bray F, Siegel RL, Ferlay J, Lortet-Tieulent J and Jemal A: Global cancer statistics, 2012. CA Cancer J Clin 65: 87-108, 2015.

2. Tamas K, Walenkamp A, de Vries E, van Vugt MA, Beets-Tan RG, van Etten B, de Groot DJ and Hospers GA: Rectal and colon cancer: Not just a different anatomic site. Cancer treatment reviews 41: 671-679, 2015.

3. Goldberg RM, Fleming TR, Tangen CM, Moertel CG, Macdonald JS, Haller DG and Laurie JA: Surgery for recurrent colon cancer: Strategies for identifying resectable recurrence and success rates after resection. Eastern Cooperative Oncology Group, the North Central Cancer Treatment Group, and the Southwest Oncology Group. Ann Intern Med 129: 27-35, 1998.

4. Sardi A, Minton JP, Nieroda C, Sickle-Santanello B, Young D and Martin EW Jr: Multiple reoperations in recurrent colorectal carcinoma. An analysis of morbidity, mortality and survival. Cancer 61: 1913-1919, 1988.

5. Beart RW: Prevention and management of recurrent rectal cancer. World J Surg 15: 589-591, 1991.

6. Sugarbaker PH: Update on the prevention of local recurrence and peritoneal metastases in patients with colorectal cancer. World J Gastroenterol 20: 9286-9291, 2014.

7. Sugarbaker PH: Second-look surgery for colorectal cancer: Revised selection factors and new treatment options for greater success. Int J Surg Oncol 2011: 915078, 2011.

8. André T, Louvet C, Maindrault-Goebel F, Couteau C, Mabro M, Lotz JP, Gilles-Amar V, Krulik M, Carola E, Izrael V and de Gramont A: CPT-11 (irinotecan) addition to bimonthly, high-dose leucovorin and bolus and continuous-infusion 5-fluorouracil (FOLFIRI) for pretreated metastatic colorectal cancer. GERCOR. Eur J Cancer 35: 1343-1347, 1999.

9. Elias D, Goere D, Blot F, Billard V, Pocard M, Kohneh-Shahri N and Raynard B: Optimization of hyperthermic intraperitoneal chemotherapy with oxaliplatin plus irinotecan at $43^{\circ} \mathrm{C}$ after compete cytoreductive surgery: Mortality and morbidity in 106 consecutive patients. Ann Surg Oncol 14: 1818-1824, 2007.

10. Elias D, Matsuhisa T, Sideris L, Liberale G, Drouard-Troalen L, Raynard B, Pocard M, Puizillou JM, Billard V, Bourget P and Ducreux M: Heated intra-operative intraperitoneal oxaliplatin plus irinotecan after complete resection of peritoneal carcinomatosis: Pharmacokinetics, tissue distribution and tolerance. Ann Oncol 15: 1558-1565, 2004.

11. Kataria T, Rawat S, Sinha S, Garg C, Bhalla N and Negi P: Dose reduction to normal tissues as compared to the gross tumor by using intensity modulated radiotherapy in thoracic malignancies. Radiat Oncol 1: 1, 2006.

12. Broders AC: The grading of carcinoma. Minn Med 8: 726-730, 1925.

13. Taylor WE, Donohue JH, Gunderson LL, Nelson H, Nagorney DM, Devine RM, Haddock MG, Larson DR, Rubin J and O'Connell MJ: The Mayo Clinic experience with multimodality treatment of locally advanced or recurrent colon cancer. Ann Surg Oncol 9: 177-185, 2002.

14. Olson RM, Perencevich NP, Malcolm AW, Chaffey JT and Wilson RE: Patterns of recurrence following curative resection of adenocarcinoma of the colon and rectum. Cancer 45: 2969-2974, 1980.

15. Willett CG, Tepper JE, Cohen AM, Orlow E and Welch CE: Failure patterns following curative resection of colonic carcinoma. Ann Surg 200: 685-690, 1984.

16. Curley SA, Carlson GW, Shumate CR, Wishnow KI and Ames FC: Extended resection for locally advanced colorectal carcinoma. Am J Surg 163: 553-559, 1992.

17. Michelassi F, Vannucci L, Ayala JJ, Chappel R, Goldberg R and Block G: Local recurrence after curative resection of colorectal adenocarcinoma. Surgery 108: 787-792, 1990.

18. Chabot GG: Clinical pharmacokinetics of irinotecan. Clin Pharmacokinet 33: 245-259, 1997.

19. Saltz LB, Cox JV, Blanke C, Rosen LS, Fehrenbacher L, Moore MJ, Maroun JA, Ackland SP, Locker PK, Pirotta N, et al: Irinotecan plus fluorouracil and leucovorin for metastatic colorectal cancer. Irinotecan Study Group. N Engl J Med 343: 905-914, 2000.

20. Cohen MS, Al-kasspooles MF, Williamson SK, Henry D, Broward M and Roby KF: Combination intraperitoneal chemotherapy is superior to mitomycin C or oxaliplatin for colorectal carcinomatosis in vivo. Ann Surg Oncol 17: 296-303, 2010. 
21. Armstrong DK, Bundy B, Wenzel L, Huang HQ, Baergen R, Lele S, Copeland LJ, Walker JL, Burger RA; Gynecologic Oncology Group: Intraperitoneal cisplatin and paclitaxel in ovarian cancer. N Engl J Med 354: 34-43, 2006.

22. Alberts DS, Liu P, Hannigan EV, O'Toole R, Williams SD, Young JA, Franklin EW, Clarke-Pearson DL, Malviya VK and DuBeshter B: Intraperitoneal cisplatin plus intravenous cyclophosphamide versus intravenous cisplatin plus intravenous cyclophosphamide for stage III ovarian cancer. N Engl J Med 335: 1950-1955, 1996.

23. Choi MK, Ahn BJ, Yim DS, Park YS, Kim S, Sohn TS, Noh JH, Heo JS, Lee J, Park SH, et al: Phase I study of intraperitoneal irinotecan in patients with gastric adenocarcinoma with peritoneal seeding. Cancer Chemother Pharmacol 67: 5-11, 2011.

24. Turcotte S, Sideris L, Younan R, Drolet P and Dubé P: Pharmacokinetics of intraperitoneal irinotecan in a pig model. J Surg Oncol 101: 637-642, 2010.

25. Mundt AJ, Mell LK and Roeske JC: Preliminary analysis of chronic gastrointestinal toxicity in gynecology patients treated with intensity-modulated whole pelvic radiation therapy. Int J Radiat Oncol Biol Phys 56: 1354-1360, 2003.
26. Uy NW, Woo SY, Teh BS, Mai WY, Carpenter LS, Chiu JK, Lu HH, Gildenberg P, Trask T, Grant WH and Butler EB: Intensity-modulated radiation therapy (IMRT) for meningioma. Int J Radiat Oncol Biol Phys 53: 1265-1270, 2002.

27. Vicini FA, Sharpe M, Kestin L, Martinez A, Mitchell CK, Wallace MF, Matter R and Wong J: Optimizing breast cancer treatment efficacy with intensity-modulated radiotherapy. Int J Radiat Oncol Biol Phys 54: 1336-1344, 2002.

28. Engstrom PF, Arnoletti JP, Benson AB III, Chen YJ, Choti MA, Cooper HS, Covey A, Dilawari RA, Early DS, Enzinger PC, et al: NCCN Clinical Practice Guidelines in Oncology: Colon cancer. J Natl Compr Canc Netw 7: 778-831, 2009.

29. Passot G, You B, Boschetti G, Fontaine J, Isaac S, Decullier E, Maurice C, Vaudoyer D, Gilly FN, Cotte E and Glehen O: Pathological response to neoadjuvant chemotherapy: A new prognosis tool for the curative management of peritoneal colorectal carcinomatosis. Ann Surg Oncol 21: 2608-2614, 2014.

30. Benoist S, Brouquet A, Penna C, Julié C, El Hajjam M, Chagnon S, Mitry E, Rougier P and Nordlinger B: Complete response of colorectal liver metastases after chemotherapy: Does it mean cure? J Clin Oncol 24: 3939-3945, 2006. 